\title{
Analysis of Smear Microscopy and Culture Conversion Results in Multidrug-Resistant Tuberculosis Patients with and without Type 2 Diabetes Mellitus
}

\author{
Fauziah $\mathrm{H}^{1}$, Aprianti $\mathbf{S}^{1,2}$, Handayani $\mathbf{I}^{1}$, Kadir $\mathrm{NA}^{2,3}$ \\ ${ }^{1}$ Department of Clinical Pathology, Faculty of Medicine, Hasanuddin University/Dr. Wahidin Sudirohusodo, Makassar, Indonesia. \\ E-mail: hennyfauziah02@gmail.com \\ ${ }^{2}$ Haji Regional Public Hospital, Makassar, Indonesia \\ ${ }^{3}$ Labuang Baji Regional Public Hospital, Makassar, Indonesia
}

\begin{abstract}
The World Health Organization (WHO) recommended microscopic AFB smear examination and culture as follow-ups to the response of MDR-TB therapy. Analyzed the results of microscopic AFB smear and culture conversion as well as treatment outcome in Multidrug-Resistant Tuberculosis (MDR-TB) patients with and without Diabetes Mellitus (DM). This is a retrospective study involved 70 MDR-TB patients with (27 patients) with DM and without DM (43 patients) who had microscopic AFB smear and culture results at the start of the follow-up therapy. This research was conducted at Labuang Baji Regional Public Hospital, Makassar, from June to July 2019, used medical records of MDR-TB patients the period of June 2016 to December 2017. The results showed that 52 out of 70 MDR-TB patients had microscopic AFB smear and culture conversion in MDR-TB with DM (21 patients) and without DM (31 patients). The duration of microscopic AFB smear conversion in MDR TB patients with DM (3.33 \pm 0.54 months) was longer than patients without DM $(2.07 \pm 0.05$ months $), p=0.001$. While in culture conversion, there was no significant difference between MDR-TB with DM (1.28 \pm 0.64 months) and without DM (1.25 \pm 0.59$)$, $p=0.648$. The recovery outcome between MDR-TB with (48.1\%) and without DM (48.8\%) was not significantly different. However, the output of treatment failure was greater in DM (11.2\%) than without DM (2.3\%), although statistically, there was no significant difference $(p=0.568)$. Multidrug-resistant tuberculosis patients with DM experienced slower microscopic AFB smear conversion than MDR-TB patients without DM. However, in culture, there was no significant difference in the conversion period between the two groups. MDR-TB patients, both of with and without DM, had the same chance of recovery.
\end{abstract}

Keywords: Multidrug-resistant tuberculosis, with diabetes mellitus, without diabetes mellitus, microscopic AFB smear, culture

\section{INTRODUCTION}

Multidrug-Resistant Tuberculosis (MDR-TB) is tuberculosis, which is resistant to Anti-Tuberculosis Drugs (ATD) against Isoniazid (INH) or rifampicin with or without other drug resistance. This is important because the management of MDR-TB becomes more complicated, requires longer treatment and causes higher treatment costs compared to non-resistant TB. ${ }^{1}$

Multidrug-resistant tuberculosis is a threat to tuberculosis control programs in various countries. The World Health Organization (WHO) reported that in 2016 there were 490,000 MDR-TB cases and 110,000 Rifampicin-Resistant (RR-TB) cases which were eligible for MDR-TB treatment. ${ }^{2,3}$

Diabetes Mellitus (DM) is one of the risk factors for tuberculosis. Since the beginning of the $20^{\text {th }}$ century, the relationship between DM and TB have been intensively observed. Diabetes mellitus increases the risk of TB 2-5 times higher than non-DM, and the risk of death during treatment and reactivation after treatment is higher than non-DM. Reactivation of TB bacteria in DM patients is very likely to cause MDR-TB. Diabetes mellitus-TB patients are more likely to have low sputum conversion and higher possibility of treatment failure. . $^{4-6}$

The diagnosis of MDR-TB is made based on the MTB sensitivity test using standard methods which are widely available in Indonesia, such as the molecular rapid test method with GeneXpert or with Line Probe Assay (LPA), conventional culture methods, and smear microscopy. Bacterial culture remains the gold standard for MDR-TB diagnosis, whereas smear microscopy together with culture is used as a follow-up to determine the therapeutic response which is characterized by the conversion of 
both tests. ${ }^{6,7}$

Treatment for MDR-TB takes 9 to 24 months, and approximately $52 \%$ of cases were declared as successful global therapy in 2013. Research by Alene et al. suggested that the conversion time for smear microscopy in MDR-TB patients was between 2-4 months, and time for culture conversion was 4-6 months. The optimal time for smear microscopy conversion and simultaneous culture conversion was four months. ${ }^{7}$ However, a similar study by Shibabaw et al., suggested that culture conversion in MDR-TB patients required three months, while microscopic smear conversion required two months. ${ }^{8}$

Studies on smear microscopy and culture in MDR-TB patients have frequently been reported in some countries; however, but research on microscopic smear conversion and culture in MDR-TB patients with or without DM in Makassar has never been reported. Based on the background above, it was necessary to carry out a study to analyze the results of microscopic smear conversion and culture and treatment outcome in MDR-TB patients with and without DM.

\section{METHODS}

This research was a retrospective study using secondary data from medical records of patients in the Labuang Baji Regional Hospital in October 2016-December 2017. The study was performed at the Medical Records Installation of Labuang Baji Regional Hospital from June to July 2019.

The study population was all patients diagnosed with MDR-TB by clinicians at Labuang Baji District Hospital. The study sample was a study population that met the inclusion criteria such as MDR-TB patients aged $\geq 18$ years diagnosed MDR-TB with and without DM and had data on smear microscopy and early culture and those of follow-up during therapy. The exclusion criteria in this study were MDR-TB patients diagnosed with HIV. The parameters assessed in this study were microscopic smear and culture in the beginning and follow-up during therapy.

Data were analyzed using the statistical independent T-test, Chi-Square, Mann-Whitney, and Log Rank test to determine the smear microscopy conversion time and culture conversion time in both groups. The test results were significant if the significance value $p<0.005$.

Research permission was obtained from the Health Research Ethics Committee of the Faculty of Medicine, Hasanuddin University/Central General
Hospital Dr. Wahidin Sudirohusodo, Makassar, and Hasanuddin University Hospital Makassar with number 570/UN4.6.4.5.31/PP36/2019.

\section{RESULTS AND DISCUSSIONS}

This study involved 70 patients who met the inclusion and exclusion criteria. The largest population of MDR-TB with DM was female, with a percentage of $51.9 \%$. The mean age of MDR-TB patients with DM was $43.81 \pm 8.22$ years. There was no significant difference in initial smear microscopy between MDR-TB patients with and without DM $(p=0.301)$, and there was no significant difference in the outcome of MDR-TB therapy between MDR-TB patients with DM and without DM ( $p=0.568)$. However, failed therapy outcomes in MDR-TB patients with DM showed a higher failure rate (11.2\%) compared to MDR-TB patients without DM (2.3\%) (Table 1).

Data analysis showed no gender differences in MDR-TB patients with and without DM.

There was no significant difference in culture conversion status and the culture conversion time between MDR-TB patients with DM and without DM with $p=0.569$ and $p=0.648$, respectively. Contrastingly, there was a significant difference in microscopic smear conversion time between MDR-TB patients with and without DM $(p=0.001)$, whereas there was no significant difference in microscopic smear conversion status between MDR-TB patients with and without DM ( $p=0.596)$ (Table 2).

The difference in conversion time of smear microscopy to the probability of conversed patients can be seen in the Kaplan Meier Curve (Figure 1). Statistical analysis using the Log Rank test showed a significant difference in conversion time of smear microscopy between MDR-TB patients with and without DM ( $p=0.001)$.

This study used a retrospective research design by involving 70 patients who met the inclusion and exclusion criteria. The results of the study (Table 1 ) showed that the highest incidence of MDR-TB in DM non-DM patients was found in the productive age with an average age of 40 years. This was in line with research by Nurbiah in Makassar, which suggested that the most MDR-TB cases were found in the age range of 45-53 years. Productive age has adequate mobilization and activity which was suggested to cause of the spread of MDR-TB. . $^{910}$

There was no significant difference in the cured outcomes after therapy (Table 1 ) between MDR-TB patients with DM (48.8\%) and without DM (48.1\%) 
Table 1. General characteristics of MDR-TB patients

\begin{tabular}{|c|c|c|c|}
\hline Parameter & DM (n=27) & Without DM (n=43) & p-value \\
\hline Gender $^{a}$ & $13(48.1 \%)$ & $21(48,8 \%)$ & \\
\hline Male & $14(51.9 \%)$ & 22 (51.2\%) & 0.955 \\
\hline \multicolumn{4}{|l|}{ Female } \\
\hline Age (years) ${ }^{b}$ & $43.81 \pm 8.22$ & $44.28 \pm 13.81$ & 0.861 \\
\hline \multicolumn{4}{|l|}{ Initial bacterial culture } \\
\hline Positive & 27 (100\%) & $43(100 \%)$ & \\
\hline \multicolumn{4}{|l|}{ The initial result of smear } \\
\hline $1+$ & 9 (33.3\%) & $12(27.9 \%)$ & 0.310 \\
\hline $2+$ & 9 (33.3\%) & 9 (20.9\%) & \\
\hline \multicolumn{4}{|l|}{$3+$} \\
\hline \multicolumn{4}{|l|}{ Therapy outcome } \\
\hline Cured & $13(48.1 \%)$ & $21(48.8 \%)$ & \\
\hline Died & 7 (25.9\%) & $14(32.6 \%)$ & \\
\hline Treatment & $4(14.8 \%)$ & 7 (16.3\%) & 0.568 \\
\hline $\begin{array}{l}\text { Discontinued } \\
\text { Failed }\end{array}$ & 3 (11.2\%) & 1 (2.3\%) & \\
\hline
\end{tabular}

Source: Secondary data a. Chi-Square b. Independent T-test

Table 2. Analysis of culture and smear microscopy conversion results in MDR-TB patients with and without DM

\begin{tabular}{|c|c|c|c|}
\hline Parameter & $\mathrm{DM}(n=27)$ & Without DM (n=43) & $\mathbf{P}$ \\
\hline \multicolumn{4}{|l|}{ Culture conversion status $^{a}$} \\
\hline Yes & $21(77.8 \%)$ & 31 (72.1\%) & 0.596 \\
\hline No & $6(22.2 \%)$ & $12(27.9 \%)$ & \\
\hline Culture conversion time (months) $^{\mathrm{b}}$ & $1.28 \pm 0.64$ & $1.25 \pm 0.59$ & 0.48 \\
\hline \multicolumn{4}{|l|}{ Smear microscopy conversion status } \\
\hline Yes & 21 (77.8\%) & 31 (72.1\%) & 0.596 \\
\hline No & $6(22.2 \%)$ & $12(27.9 \%)$ & \\
\hline $\begin{array}{l}\text { Smear microscopy conversion time } \\
\text { (months) }^{c}\end{array}$ & $3.33 \pm 0.55$ & $2.07 \pm 0.05$ & 0.001 \\
\hline
\end{tabular}

a. Chi-Square test b. Mann-Whitney c. Log Rank (Mantel-cox) Significant if p-value $<0.05$

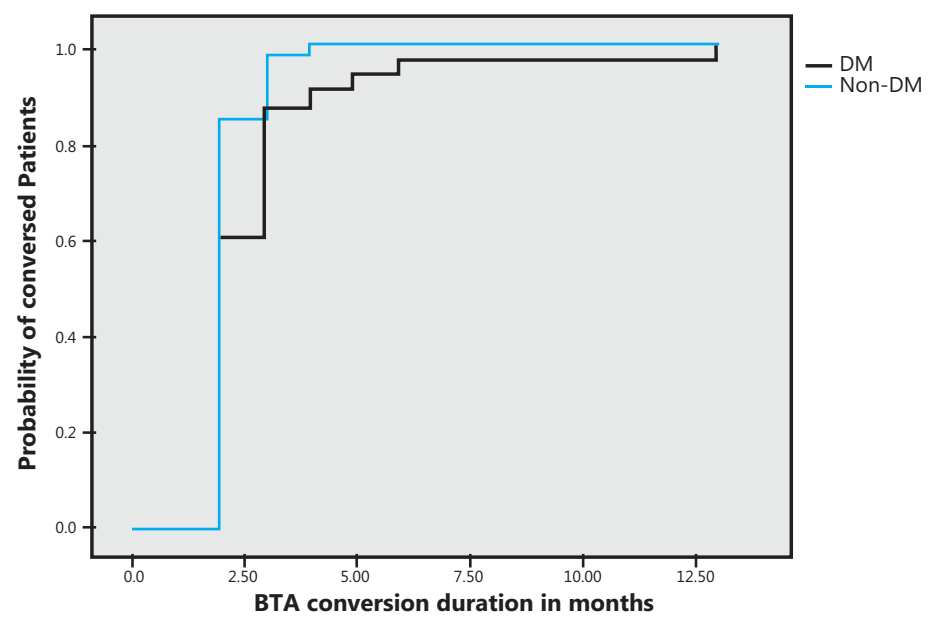

Figure 1. Kaplan Meier Curve

(Conversion time of smear microscopy to the probability of conversed patients) 
with $p$-value $=0$ (Table 1 ). This was in line with research by Munoz et al. in Mexico, which found no statistically significant difference in the cured outcomes between MDR-TB patients with DM and without DM $(p=0.07){ }^{11}$

The World Health Organization (WHO) introduces integrated management for the treatment of drug-resistant TB patients known as the Integrated Management of Drug-Resistant TB Control/Manajemen Terpadu Pengendalian TB Resistan Obat (MTPRO). The MTPRO program includes a component of MDR-TB control management, one of which is the appropriate treatment strategy by the administration of rational anti-TB drugs, especially in the treatment of special circumstances with DM, treatment accompanied by trained drug-swallowing supervisors/Badan Pengawas Menelan Obat (PMOs), and permanent monitoring procedures to overcome adverse events were any of factors which enable a successful recovery in MDR-TB patients both with and without DM. ${ }^{10,11}$

The failed therapy outcome in MDR-TB patients with DM has a slightly larger proportion (11.2\%) compared to those without DM (2.3\%). This was in line with research by Masishale et al. in India which suggested that pulmonary TB and DM with poor initial glycemic control have slow sputum conversion and have high treatment failure. ${ }^{12}$ Baker et al. stated that TB patients with DM lead to a risk of treatment failure, death, and recurrence rate after TB therapy. ${ }^{13}$

Immunologic response of a person with DM will decrease, hyperglycemic state causes impaired neutrophil and lymphocyte function, thus decreasing phagocytic function and bacterial killing activity, and causes decreased cellular immunity such as T helper (Th1) cytokines consisting of TNF- alpha, IL-1 beta, and IL- 6 . Th1 cytokines play an important role in controlling and limiting MTB infection. Decreased immune function is one of the factors causing the failure of therapy in MDR-TB patients with DM. ${ }^{14}$

Based on the results of culture conversion in MDR-TB patients with and without DM (Table 2), no significant differences were found in both the status and duration of culture conversion. This was in line with research by Magee et al., in Georgia who suggested that there was no significant difference in culture conversion between MDR-TB patients with $\mathrm{DM}$ and without DM. ${ }^{15}$

Differentiation between dead and living bacteria and differentiation between MTB and
Non-Tuberculosis Mycobacteria (NTM) can be carried out by culture examination. With good culture techniques, positive results will be obtained if living bacteria range from 10 - 100 bacteria per $\mathrm{mL}$. This makes the culture more specific to identify MTB which grows in solitude; therefore, treatment of MDR-TB patients both with or without DM according to rational drug administration can help killing process of MTB and accelerate culture conversion time. ${ }^{16}$

The conversion time of smear microscopy in MDR-TB patients with DM and without DM (Table 2) was significant $(p=0.001)$ in this study. MDR-TB patients with $\mathrm{DM}$ had a longer conversion time (3.33 \pm 0.54 months) compared to that of non-DM MDR-TB patients $(2.07 \pm 0.04$ months). This was in line with research by Cornelio et al., in West, Kalimantan suggesting that there was a tendency of late smear microscopy conversion in DM patients; thus increasing tuberculosis transmission. ${ }^{17}$

Research by Viswanathan et al., in South India found that there was a delay in smear microscopy conversion in MDR-TB patients with DM with a mean conversion of 70 days and 60 days in non-DM MDR-TB patients $(p=0.001)$. Also, there was a high failure rate in MDR-TB patients with DM compared to MDR-TB patients without DM. ${ }^{18}$

Smear microscopy is the simplest, quickest, most reliable, and the most reasonable test to diagnose TB. The specificity of microscopic AFB is $99 \%$ in countries where NTM cases are still low. However, to date, there have been no reports on the prevalence of NTM in Indonesia. Microscopic smear has a sensitivity value of approximately $60 \%$ when compared to culture. ${ }^{16,19}$

Not limited to MTB, bacteria found in microscopic smear can also be groups of acid-resistant bacteria from different species. A hyperglycemic state is a supportive environment for the growth and development of MTB; therefore, in certain circumstances, smear can be positive while the culture is negative. This is one of the factors causing slower microscopic AFB conversion, especially in DM patients. ${ }^{16}$

Multidrug-resistant tuberculosis patients with DM had a longer conversion time of microscopic smear compared to MDR-TB patients without DM. However, there were no significant differences in the conversion time of bacterial culture between both groups. MDR-TB patients, both with DM and without $\mathrm{DM}$, have the same possibility of recovery. In further studies, it is necessary to include glycemic control 
data $(\mathrm{HbAlc})$ as a factor that can affect smear microscopy conversion and culture in MDR-TB patients with and without DM.

\section{CONCLUSIONS AND SUGGESTION}

Multidrug-resistant tuberculosis patients with DM experience microscopic smear conversion longer than MDR-TB patients without DM. But culturally, there were no significant differences in conversion time between the two. Multidrug-resistant tuberculosis patients, both with DM and without DM, have the same chance of recovery. In further studies, it is necessary to include glycemic control data (HbA1c) as a factor that can affect microscopic smear conversion and culture in MDR-TB patients with DM and without DM.

\section{REFERENCES}

1. Kementrian Kesehatan RI. Petunjuk teknis manajemen terpadu pengendalian tuberkulosis resistan obat. Jakarta, Direktorat Pengendalian Penyakit dan Penyehatan Lingkungan, 2014; 2.

2. World Health Organization. What is multidrug-resistant tuberculosis (MDR-TB) and how do we control it. https://err.ersjournals.com/content/28/152/190035. accessed 8 July, 2019.

3. Fachri M, Hatta M, Abadi S, Santoso SS, Wikanningtyas TA, dkk. Comparison of Acid Fast Bacilli (AFB) smear for Mycobacterium tuberculosis on adult Pulmonary Tuberculosis (TB) patients with type 2 Diabetes Mellitus (DM) and without type 2 DM. Respiratory Medicine Case Reports, 2018; 1(23): 158-62.

4. Dousa KM, Hamad A, Alsoub H, Elzouki AN, Alwakeel $\mathrm{MI}$, et al. Impact of diabetes mellitus on the presentation and response to treatment of adults with pulmonary tuberculosis in Qatar. Oxford University Press, in Open Forum Infectious Diseases, 2018; 5(1): S274.

5. Badawi A, Sayegh S, Sallam M, Sadoun E, Al-Thani M, et al. The global relationship between the prevalence of diabetes mellitus and incidence of tuberculosis: 2000-2012. Global Journal of Health Science, 2015; 7(2): 183.

6. Rasool G, Khan AM, Mohy-Ud-Din R, Riaz M. Detection of Mycobacterium tuberculosis in AFB smear-negative sputum specimens through MTB culture and GeneXpert ${ }^{\circledR}$ MTB/RIF assay. International Journal of Immunopathology and Pharmacology. 2019; 33: 2. https://journals.sagepub.com/doi/full/10.1177/2058 738419827174. Accessed 26 June, 2019.

7. Alene KA, Viney K, Yi H, McBryde ES, Yang K, et al. Comparison of the validity of smear and culture conversion as a prognostic marker of treatment outcome in patients with multidrug-resistant tuberculosis. PLos One. 2018; 23: 13(5): https://www.ncbi.nlm.nih.gov/pmc/articles/PMC5965 863/. Accessed 2 July, 2019.

8. Shibabaw A, Gelaw B, Wang SH, Tessema B. Time to sputum smear and culture conversions in multidrug-resistant tuberculosis at University of Gondar Hospital, Northwest Ethiopia. PLos One. 2018; 13(6): 2. https://www.ncbi.nlm.nih.gov/pmc/articles/ PMC6019386/. Accessed 8 July, 2019

9. Alene KA, Viney K, Yi H, McBryde ES, Yang K, et al. Comparison of the validity of smear and culture conversion as a prognostic marker of treatment outcome in patients with multidrug-resistant tuberculosis. PLos One. 2018; 23: 13(5): 9.

10. Nurbiah N. Gambaran faktor risiko pengobatan pasien Multidrug-Resistance Tuberculosis (MDR-TB) di RSUD Labuang Baji Kota Makassar Tahun 2017 (Doctoral dissertation, Universitas Islam Negeri Alauddin Maksassar).

11. Yanti, Zeni. Pengaruh Diabetes melitus terhadap keberhasilan pengobatan TB paru di Puskesmas Tanah Kalikedinding. Jurnal Berkala Epidemiologi, 2017; 5: 163-173.

12. Munoz-Torico, Luna JC, Migliori GB, D'Ambrosio L, Carrillo-Alduenda, et al. Comparison of bacteriological conversion and treatment outcomes among MDR-TB patients with and without diabetes in Mexico: Preliminary data. Revista Portuguesa de Pneumologia (English Edition), 2017; 23(1): 27-30.

13. Mahishale $V$, Avuthu $S$, Patil B, Lolly $M$, Eti $A$, et al. Effect of poor glycemic control in newly diagnosed patients with smear-positive Pulmonary tuberculosis and type-2 diabetes mellitus. Iranian Journal of Medical Sciences, 2017; 42(2): 144.

14. Baker MA, Harries AD, Jeon C, Hart JE, Kapur A, et al. The impact of diabetes on tuberculosis treatment outcomes: A systematic review. BMC Medicine, 2011; 9(1): 81

15. Mihardja L, Lolong DB, Ghani L. Prevalensi diabetes melitus pada tuberkulosis dan masalah terapi. Jurnal Ekologi Kesehatan, 2015; 14(4): 350-358.

16. Magee MJ, Kempker RR, Kipiani M, Tukvadze N, Howards PP, et al. Diabetes mellitus, smoking status, and rate of sputum culture conversion in patients with multidrug-resistant tuberculosis: A cohort study from the country of Georgia. PLos One, 2014; 9(4): e94890.

17. Departemen Kesehatan RI. Modul kultur dan uji kepekaan M.tuberculosis terhadap obat anti tuberculosis lini pertama. Jakarta, Departemen Kesehatan RI, 2008; 15.

18. Viswanathan V, Vigneswari A, Selvan K, Satyavani K, Rajeswari $R$, et al. Effect of diabetes on treatment outcome of smear-positive pulmonary tuberculosis-A report from South India. Journal of Diabetes and its Complications, 2014; 28(2): 162-165.

19. Sarin R, Singla R, Visalakshi $P$, Jaiswal A, Puri MM, et al. Smear microscopy as surrogate for culture during follow-up of pulmonary MDR-TB patients on DOTS plus treatment. Indian J Tuberc, 2010; 57(3): 134-140. 